\title{
Abrindo telas em smartphones e contemplando novas formas de numeramento
}

\author{
Wagner Marques \\ UCAM/FAETEC \\ wagsm@ig.com.br
}

\section{Marcelo Bairral \\ UFRRJ \\ mbairral@ufrrj.br}

\begin{abstract}
Resumo
Investigar a questão do numeramento mediante a implementação de atividades instigadoras com a utilização de smartphones é o que pretendemos acossar. Como consequência, uma atitude preliminar consiste em catalogar pesquisas que possam ser norteadoras para nosso propósito. Assim, apresentamos o recorte de uma pesquisa de doutorado em andamento, o qual elenca estudos acerca do numeramento. Este levantamento inicial sinaliza que no Brasil o foco predominante tem sido a Educação de Jovens e Adultos, ao passo que no exterior encontramos aplicações voltadas às séries iniciais. Destacamos também uma prática de numeramento peculiar que projeta especulações sobre diferentes tipos de numeramento, ou seja, o escolar e o do cotidiano. Como tais pesquisas não explicitam o uso de tecnologia, imaginamos ter o desafio de fazê-lo, e, assim, apresentamos uma atividade pautada no uso do aplicativo MyScript Calculator, com o objetivo de apresentar uma revisão de literatura inicial e ilustrar uma implementação de atividade com alunos do Ensino Médio de uma escola da rede pública, sob uma abordagem intervencionista.
\end{abstract}

Palavras-chave: Numeramento. Smartphones. Atividades Instigadoras.

\section{New forms of numeracy by opening screens on smartphones}

\begin{abstract}
Investigating the issue of numeracy by implementing instigating activities with the use of smartphones is what we intend to harass. As a consequence, a preliminary attitude is to catalog research that may be guiding to our purpose. Thus, we present the cut of a doctorade research in progress, which lists studies on numeracy. This initial survey indicates that in Brazil the predominant focus has been the Education of Young people and Adults, while abroad we find applications focused on the initial series. We also emphasize a peculiar numbering practice that projects speculations on different types of numbering, that is, the school and daily life. As such research does not explicitly state the use of technology, we think we have the challenge of doing so, and thus present an activity guided by the use of the MyScript Calculator application, with the purpose of presenting an initial literature review and illustrating an activity implementation with high school students from a public school under an interventionist approach.
\end{abstract}

Keywords: Numeracy. Smartphones. Instigating activities. 


\section{Abrindo a tela}

Um simples toque hoje numa tela sensível, também chamada de touchscreen, é capaz de realizar ações jamais pensadas mesmo com a utilização do mouse de um computador. Muitos jovens podem acabar se sentindo motivados para aprender, quando se utiliza esse tipo de tecnologia aliada a tarefas com o propósito de conduzir a explorações e descobertas. Dentro dessa perspectiva, entendemos que a utilização de atividades instigadoras (MARQUES; BAIRRAL, 2014), associada à epistemologia construcionista (ESTEBAN, 2010), venha a sugerir uma apropriação desse recurso dentro do cenário educativo. Assim, movidos por este impulso, pretendemos investigar como pode ocorrer a inserção de smartphones em aulas de matemática mediante o uso de atividades instigadoras, mais especificamente voltadas à questão do numeramento. No intuito de estimular práticas de numeramento, trazemos uma proposta pautada em (i) investigar que softwares/aplicativos/jogos podem ser utilizados nessa implementação com alunos do Ensino Médio, (ii) inserir tecnologia touchscreen em sala de aula, mediante a implementação de atividades instigadoras que incitem práticas de numeramento, e (iii) analisar possíveis contribuições para a aprendizagem dos alunos desse segmento quando submetidos a esse tipo de prática.

Compactuamos com a ideia de que o conhecimento pode ser construído a partir das interações, de práticas humanas, projetando nossa proposição no sentido de envolver atividades que deverão ser realizadas, desejavelmente, em duplas. Pretendemos realizar nossa implementação de modo intervencionista (SPINILLO; LAUTERT, 2008), uma vez que se trata de um tipo de pesquisa entusiasta pelas possibilidades cognitivas que emergem durante o plano de intervenções, com interesse pela modificabildade, pelo movimento, pelo processo, ou seja, um método que pretende (des)envolver aspectos relevantes às habilidades a serem elevadas. Desta forma, optaremos por utilizar, a fim de registrar os encontros e colher o material produzido, recursos como vídeos, gravação de áudios, fotografias, folhas de respostas e de comentários preenchidas pelos discentes, além da confecção de um diário de campo.

Neste momento, debruçamo-nos sobre revisão de literatura sobre o tema numeramento, a fim de sondar os tipos de pesquisas que têm sido realizadas, bem como a metodologia adotada e os sujeitos investigados, tanto em cenário nacional como internacional. Desta forma, fazemos este recorte da nossa pesquisa de doutorado que se encontra em andamento, com o objetivo de descobrir e estabelecer possíveis intercessões de outras averiguações com nossa proposição, elencando, a seguir, leituras por nós realizadas, além de ilustrarmos uma implementação de atividade com alunos do Ensino Médio de uma escola da rede pública. 


\section{Telas "numeradas"}

As necessidades presentes no cotidiano fazem com que os indivíduos "[...] desenvolvam capacidades de natureza prática para lidar com a atividade matemática, o que lhes permite reconhecer problemas, buscar e selecionar informações, tomar decisões" (BRASIL, 1998, p. 37). No entanto, em alguns casos, para atingir essas capacidades, torna-se necessária a adoção de outros tipos de habilidades como ler, escrever e se comunicar, em conjunto com as habilidades matemáticas.

Inspirado pelas discussões sobre letramento, as quais vinham incluindo comentários sobre matemática, Barwell (2004) sublinha como pesquisas em educação matemática começaram a discutir sobre a importância do numeramento, vinculando-o a práticas sociais. Toledo (2004, p. 94) sinaliza "[...] um novo fenômeno, o numeramento, como um domínio de habilidades que envolve um subconjunto de habilidades essenciais tanto da matemática como do letramento", promovendo uma integração entre esses conhecimentos. Ferreira e Fonseca (2015) sublinham que esta manifestação se refere a práticas sociais que, impregnadas por cultura escrita, estimulam conhecimentos relacionados às ações de quantificar, ordenar, organizar e medir.

Partindo do princípio de que estratégias metacognitivas de pensamento são deficientes, ou mesmo ausentes, como forma de consciência do sujeito, Toledo (2002) propôs uma investigação acerca do papel do numeramento na aprendizagem de adultos pouco escolarizados, por considerar essa prática um dos principais pilares para a aquisição e construção de conhecimentos matemáticos, buscando possíveis relações entre o desenvolvimento desse tipo de estratégia e a evolução do registro matemático do público envolvido.

A pesquisa pautou-se na observação do desempenho de cinco estudantes do ensino fundamental de um curso supletivo, de uma escola situada na Zona Leste de São Paulo, tendo sido colhidos os dados mediante aplicação de atividades, registros matemáticos e entrevistas, tudo com o grupo escolhido. A partir dessas informações, a estudiosa sinaliza que houve indícios do grau de adoção de formas escolares nos registros matemáticos, bem como foi revelada pelas entrevistas certa percepção de processos de pensamento pelos sujeitos, concorrendo para uma relação na qual existe uma influência recíproca entre metacoginição e registro. Desta forma, a pesquisadora sugere o numeramento como uma via a ser esmiuçada e discutida como possibilidade para qualificar essa relação.

Baker, Street e Tomlin (2003), estudiosos da linha práticas de numeramento na escola e na comunidade, do projeto de pesquisa Leverhulme Numeracy Programme, realizado no período de 1997 a 2002, apresentaram um recorte da pesquisa de Alison Tomlin, o qual investigou a questão do numeramento em três escolas inglesas, a partir de um pequeno excerto do diário de campo deste 
pesquisador, no qual descreve sua visita à residência de Aaysha, aluna sujeito de sua averiguação, pertencente a uma família paquistanesa que havia imigrado para o Reino Unido.

Tomlin havia observado na escola, ao solicitar que Aaysha contasse quantos alunos estavam presentes, uma maneira diferente de fazê-lo, utilizada pela estudante, ao contar de três em três com o uso de cada dedo. Em sua primeira visita à casa da aluna, cuja família vivia sob condições bem pobres, o estudioso conversou com o pai dela e questionou sobre aquela maneira de contar, na tentativa de descobrir se era um ensinamento aprendido dentro de casa, ou seja, se ele ensinava esse método aos filhos. Não houve qualquer tipo de confirmação, o que, aparentemente, mostrava que a menina aprendera apenas observando tal prática. O senhor Anwar, pai de Aaysha, explicou que aquela maneira de contar conseguia atingir o número trinta, ou mesmo sessenta quando se dobrava uma falange para indicar seis unidades a cada dedo (o dobro), sendo possível contar mais do que o modo que se aprendia na escola, contando de um em um, chegando apenas a dez.

Em sua segunda visita, a mãe da estudante revelou algumas habilidades que a filha havia desenvolvido, como ajudar na culinária em relação a medidas com copos, a escolher livros em uma biblioteca, e, quando inquirida sobre aquele método de contagem, a senhora Anwar disse que agora Aaysha sabia contar das duas formas e estava usando bastante a forma aprendida na escola. Baker, Street e Tomlin (2003) interpretaram essa contagem realizada pela aluna, de três em três, como um exemplo de práticas de numeramento que são diferentes em alguns aspectos daquelas da escola. É possível, então, reconhecer que tais práticas podem diferir em termos de significados, relações sociais entre diferentes lares, e entre a casa da criança e a escola que frequenta, pois envolvem diferentes relações sociais e procedimentos da casa oriundos de casa ou da escola.

Os estudiosos identificaram ainda que este exemplo de pobreza em si não era suficiente para a determinação do insucesso, tendo em vista que se trata de uma casa que é relativamente pobre em um sentido financeiro, mas cuja família é composta por pessoas qualificadas, motivadas e confiantes, o que permite o investigador se concentrar em valores, crenças e escolhas determinantes para a prática do numeramento em casa. Esta abordagem concede subsídios para identificação, análise e comparações entre práticas de numeramento localizadas em diferentes contextos sociais, especialmente em casas e escolas.

Dentro dessa perspectiva, Baker, Street e Tomlin (2003) sinalizam que, se contextos familiares e escolares são diferentes, de modo a afetar a realização da escolarização infantil, faz-se necessário, então, entender em que medida práticas de numeramento são diferentes, uma vez que as relações sociais que se referem à situação, papéis e identidades dos indivíduos em termos de 
numeramento em relação a outros são constitutivas de controle, de legitimidade, de status e de privilégios.

Em Queensland, estado do nordeste da Austrália, foi implementado o Projeto de Pesquisa em Numeramento e Novas Iniciativas ${ }^{1}$, do qual Baturo e Vincent (2004), dois dos dez pesquisadores que compuseram a equipe, apresentaram algumas descobertas acerca desse projeto que reuniu oito escolas, com a colaboração de professores e funcionários das mesmas, cujo objetivo foi identificar elementos necessários para a construção de ambiente de aprendizagem que pudesse promover resultados em termos de numeramento.

O modelo da averiguação, descrito pelos estudiosos como uma combinação de estudo de caso com pesquisa-ação colaborativa, permitiu elencar elementos principais para comporem um núcleo voltado à constituição do clima em favor do desenvolvimento do numeramento, como conhecimento matemático e pedagógico do professor, planejamento para as aulas, aprendizagem ativa mediante a utilização de ferramentas e discussões com os alunos, investigação (empatia, tipos de tarefas, uso de terminologias matemáticas e diálogo para desenvolvimento e validação de questões) e engajamento em sala de aula (motivação, perseverança e confiança dos estudantes nos envolvidos).

Aprendizagem ativa e investigação em sala de aula foram elementos sinalizados por Baturo e Vincent (2004), destacando-se as ferramentas e a discussão aluno x professor como potencializadores para a criação de um ambiente ativo-construcionista para obtenção de melhores resultados relacionados às questões de numeramento. No contexto da aprendizagem ativa, os pesquisadores sublinham que essas ferramentas não devem limitar a emergência de ideias matemáticas e que modelos não prototípicos devem ser introduzidos. Quanto à discussão, embora em alguns casos tenha ficado restrita a meras informações quanto a respostas certas ou erradas, foram observadas estratégias utilizadas pelos docentes, ditos experientes, no intuito de desafiar o estudante, levando-o a participar em defesa ao seu próprio ponto de vista e até mesmo de seus companheiros.

Quatro questões pertinentes à investigação em sala de aula (empatia, tarefas, terminologias e diálogo) despontaram como elementos contribuintes para melhores resultados em termos de numeramento. Nos casos em que houve presença de comunicação empática, os alunos se sentiram encorajados e puderam superar suas deficiências em favor de uma aprendizagem matemática. Em outra perspectiva, à medida que os professores abandonavam as tarefas propostas pelos livros didáticos e inseriam outros tipos de atividades, os alunos acabavam descobrindo mais de uma estratégia de solução, o que os deixava mais motivados, engendrando discussões. A percepção de

\footnotetext{
${ }^{1}$ Tradução nossa.
} 
que nem toda terminologia usada na matemática fazia parte do vocabulário dos estudantes e que isso se tornava um empecilho à aprendizagem disparou nos educadores o improviso de determinadas terminologias que estivessem ao nível de entendimento dos discentes. Em consonância aos elementos apresentados, Baturo e Vincent (2004), sublinham, ainda, que o fato de os professores permitirem e encorajarem seus discípulos a discordarem deles não somente oportunizava a aprendizagem matemática como se tornava uma possibilidade de o diálogo ocorrer fora do ambiente de sala de aula, envolvendo outros sujeitos.

Desta forma, as pesquisadoras sinalizam que as colaborações do projeto de pesquisa impactaram positivamente sobre o conhecimento matemático dos professores, como os mesmos se comportam em relação ao ensino da matemática, levando ao engajamento em sala de aula, além de auxiliar no planejamento de atividades com base no conhecimento prévio dos alunos, na escolha de recursos adequados, no gerenciamento das discussões e na revisão da postura do educador em sala de aula. Como decorrência do desafio sofrido pelos professores quanto à sua metodologia e sistema de avaliação, houve significativa mudança nas práticas e, assim, as aulas foram aprimoradas convergindo para uma melhoria de resultados dos alunos em termos de numeramento.

Em busca de uma possível relação entre numeramento e escolarização, Toledo (2004) realizou investigação sob a forma de estudos de caso, a partir de dados quantitativos elencados pelo $2^{\circ}$ Indicador Nacional de Alfabetismo Funcional (INAF 2002). Após entrevista aplicada a dois mil sujeitos, foi retirada uma amostra de referência de vinte e um sujeitos, considerados de baixo (apenas $1^{\text {a }}$ série do Ensino Fundamental) ou nenhum grau de escolarização (sem passagem pela educação formal), mas com elevado nível de alfabetismo matemático, níveis 3 e 2 (INAF, 2002), a fim de mapear suas respostas em relação (i) ao desempenho em tarefas cotidianas envolvendo quantidades, (ii) a hábitos de leitura e escrita e (iii) ao desempenho em tarefas envolvendo gráficos e tabelas.

A estudiosa observou que a maior parte dos envolvidos apresentavam dificuldades com leitura e escrita, embora possuíssem certa habilidade para lidar com números e contas, traduzida pela leitura de etiquetas de preços, de placas e cartazes envolvendo números, além da realização de contas pequenas de forma mental. Entretanto, tarefas matemáticas mais elaboradas, demandando certo nível de análise, como gráficos e tabelas, fugiam aos seus domínios, diferentemente daquelas do cotidiano, mesmo tendo sido identificada maestria para resolver situações rodeadas por números e contas.

Hábitos de leitura e escrita, uso da matemática nas tarefas diárias, escolaridade e classe social foram indicativos levantados sobre os sujeitos, mas que não permitiram explicar o desempenho dos mesmos. Desta forma, a pesquisadora sinaliza que condições muito particulares, 
peculiares, intrínsecas de cada participante possam ter determinado a apreensão dos conteúdos abordados em cada tarefa, creditando as habilidades de numeramento às demandas do meio ao qual o sujeito pertence.

No intuito de validar as estruturas das habilidades informais de numeramento de alunos das séries iniciais de escolas norte-americanas, Purpura e Lonigan (2013) investigaram sobre os domínios de numeração (conhecimento das regras e processos para sequência de contagem, de relações (percepção de como dois ou mais itens são ligados ou relevantes um para o outro) e de operações aritméticas (entendimento de maneiras como grupos são compostos e decompostos), bem como sobre a possível relação entre esses três domínios. Contagem verbal, contagem crescente, identificação de erros, estruturas e resultados de contagem, cardinalidade, subconjuntos e procedimentos de estimativa foram considerados elementos de numeração. Para representar as relações, foram elencados números ordinais, grandeza relativa, comparação e identificação de números, sequências, reprodução e comparação entre conjuntos. Ficaram a cargo das operações aritméticas adição e subtração com e sem o uso de objetos, equivalência inicial, conjuntos equivalentes, adição de dois conjuntos, composição, decomposição e combinação de números.

Os sujeitos investigados foram trezentos e noventa e três crianças de faixa etária compreendida entre três e seis anos de idade, sem quaisquer tipos de distúrbios de desenvolvimento conhecidos, oriundas de quarenta e cinco escolas tanto da rede pública como da rede privada de ensino, destinadas aos filhos de famílias de baixo para médio nível socioeconômico, as quais foram avaliadas com a utilização de testes para habilidades precoces de numeramento em idade préescolar. Essas avaliações eram compostas por subtestes, contendo sete a nove tarefas cada, implementadas em ordem não previamente estabelecida em horário distinto do das aulas, com duração aproximada de trinta minutos, com o propósito de averiguar os domínios específicos (numeração, relações e operações aritméticas).

O estudo foi constituído em três etapas, na qual a primeira voltou-se para a validação de cada domínio mediante análises exploratória e confirmatória, para assegurar a elaboração de tarefas que realmente avaliassem o construto almejado, a segunda no sentido de concluir a avaliação das relações entre os construtos, baseada em modelos de habilidades informais de numeramento, comparando com os explicitados pelo Conselho Nacional de Professores de Matemática (NCTM 2000) e pela Conferência Nacional de Leitura (NRC 2009), ambos dos Estados Unidos, e a terceira pautada em um modelo de invariância sobre grupos múltiplos, a fim de examinar se o mesmo modelo era bem aplicado tanto para crianças em idade pré-escolar (jardim de infância), como para aquelas das classes de alfabetização. 
Em relação à validação dos domínios, os investigadores sinalizaram que todos os domínios foram identificados, tendo surgido correlações entre estruturas de contagem e cardinalidade, bem como entre equivalência inicial e adição/subtração de conjuntos. $O$ modelo de três fatores (numeração, relações e operações aritméticas) mostrou-se com bom ajuste em relação aos usados para comparação, por apresentar tarefas significativamente carregadas com seu respectivo conteúdo, suportando, dessa forma, os construtos de cada domínio individual e indicando que as tarefas de cada suposto domínio estavam aptas a serem utilizadas na pesquisa. Sob um aspecto geral, esse modelo de três fatores encaixou-se bem, mesmo diante das variações de faixas etárias das crianças que compuseram os sujeitos da pesquisa, ou seja, a aplicabilidade foi possível nos grupos como um todo, designando o modelo como estável.

Diante da perspectiva apresentada, Purpura e Lonigan (2013) sublinham que as habilidades informais de numeramento de crianças em idade pré-escolar ficaram melhores representadas quando investigadas sob as lentes da numeração, das relações e das operações algébricas, resultados consistentes com os modelos apresentados no NCTM 2000 e na NRC 2009. Os pesquisadores ressaltam que o estudo diferencia-se dos anteriormente utilizados, uma vez que os três domínios ainda não haviam sido investigados em conjunto, o que limitava a amplitude das tarefas, deixando de incluir uma gama de atividades, além da possibilidade de agrupar ou combinar esses domínios. Desta forma, os estudiosos argumentam que a implementação da estrutura de três fatores (numeração, relações e operações algébricas) pode oferecer um alicerce para futuras explorações em busca de elementos centrais do desenvolvimento de habilidades informais de numeramento.

Adelino e Fonseca (2014) decidiram pesquisar sobre os livros didáticos destinados ao aos estudantes dos programas de Educação de Jovens e Adultos (EJA), especificamente o segundo segmento do ensino fundamental, como reflexão ao efetivo direito escolar conferido a essa categoria, primeiramente, a partir da criação do Programa Nacional do Livro Didático para a Alfabetização de Jovens e Adultos, em 2007, e, posteriormente, em 2011, a efetiva distribuição desse material para todo o ensino fundamental da EJA, tendo em vista a observância da escassez de averiguações acerca dos livros didáticos dirigidos a esse público.

Para avaliação desse material, as estudiosas demonstraram preocupação em contemplar aspectos socioculturais da matemática, evitando, desta forma, algum tipo de abordagem que considerasse apenas a redução do tempo dessa modalidade de ensino, bem como das limitações da compreensão dos processos de aprendizagem de seus estudantes, reconhecendo na prática de numeramento um bom subterfúgio para proceder a análise dos livros, o que parece convergir para a importância dos aspectos políticos e sociais que possam estar impregnados nesses textos, em atenção aos pressupostos ideológicos. Destacam a importância do livro didático para os programas 
de EJA, pelo fato de a maioria acontecer à noite, quando não se tem bibliotecas disponíveis e pelo baixo poder aquisitivo do seu público que os impede de ter acesso aos materiais, além da falta de formação específica para os docentes que atuam nesses programas.

As pesquisadoras examinaram cinquenta atividades voltadas à compreensão dos números naturais, dos livros didáticos da Coleção Viver, aprender, não somente pela importância de tal conteúdo, mas por creditarem a esses exercícios a tenuidade de aspectos conceituais relacionados a contextos práticos, para as quais foi elaborada uma ficha, contendo a identificação, a descrição da atividade e as categorias analítico-descritivas (contextualização, habilidades matemáticas mobilizadas e práticas de numeramento envolvidas). Dentre as práticas de numeramento identificadas pelas autoras, comunicação por meio da matemática, controle na produção do conhecimento, lógica de argumentação, repetição como estratégia de aprendizagem e recursos de cálculos matemáticos, foram eleitas para foco das discussões em sua pesquisa as práticas relacionadas à comunicação por intermédio da matemática, tendo como principal aspecto mobilizado a valorização de diversos tipos de texto que fazem parte do cotidiano dos alunos da EJA.

Tendo em vista a busca pela intencionalidade das atividades que compõem os livros didáticos investigados, Adelino e Fonseca (2014) detectaram textos oriundos de outros âmbitos (receita de doce, nota fiscal, publicação de jornal e planta baixa residencial) para serem utilizados na matemática, os quais apresentam potencial para despertar o interesse dos estudantes da EJA, destacando, desta forma, a importância da prática da leitura, uma vez que são elementos recorrentes no contexto social desse grupo. Como consequência dessa busca, algumas intenções foram identificadas, como (i) as representações dos números e distintas formas de utilizá-las, (ii) enfoque contextualizado, (iii) ensino de fração relacionado à representação decimal, (iv) valorização de ideias, (v) apropriação de práticas de numeramento com conceitos, referências estatísticas e tratamento da informação, (vi) práticas de numeramento relativas à leitura de textos próximos da vida dos alunos, (vii) recursos matemáticos ampliadores da prática da leitura, (viii) métodos didáticos diferenciados e (ix) utilização de recursos de linguagem.

Analisando tensões entre conhecimentos cotidianos e escolares presentes em aulas de matemática da Educação de Jovens e Adultos, Ferreira e Fonseca (2015) acossaram aspectos da educação matemática que pudessem contribuir para a relação entre esses saberes, uma vez que existe não só a apreensão em se trazer as vivências dos alunos para a sala de aula, como a valorização da chamada matemática formal. A fim de possibilitar o alcance de seus objetivos, as estudiosas realizaram observações em uma turma do primeiro ano do Ensino Médio, de uma escola pública de Minas Gerais, durante cinco meses, além de empreenderem entrevistas com os sujeitos 
da pesquisa, tendo sido utilizados como instrumento de coleta de dados gravações em áudio, as quais se transformaram em narrativas sobre cada aula, e anotações em diário de campo.

Ao elegerem a tentativa de resolução de um exercício por duas alunas para ser examinada, as pesquisadoras encontraram indícios da transição entre vivências de contextos extraescolares e a matemática ensinada na escola. Tratava-se de uma expressão numérica zero menos um, a qual causou indignação a uma das estudantes, que não conseguia perceber a possibilidade de realizar tal operação, pois, cingida por seus conhecimentos do cotidiano, entendia como única realidade, naquele momento, que seria impossível tirar um de nada. Admitindo a perspectiva de terem cometido algum equívoco na resolução da tarefa, as discentes a refazem, encontrando a mesma expressão ao final. No entanto, ao recorrerem aos domínios matemáticos escolares, conseguem se lembrar de outro universo no qual é possível subtrair um de zero, resultando em um número negativo.

Consoante com o exposto, Ferreira e Fonseca (2015) sinalizam que o fato de a aluna não admitir solução para o exercício inicialmente, com o uso de saberes do cotidiano, pode indicar consciência de que seria necessário transitar de uma racionalidade para outra, ou seja, percorrer um caminho em direção à matemática dita escolar. É um movimento em que as estudantes trazem seus recursos cotidianos expressivos para lidar com práticas de numeramento em sala de aula, identificada, nesse caso, como a escolha de que tipo de ferramenta torna-se mais adequada para resolver determinada situação. A postura dialógica, pautada em processos de negociação de significados, viabiliza o aparecimento das tensões entre os tipos de conhecimento, provocando a locomoção de um campo a outro, a qual oportuniza estudantes a ir além dos procedimentos escolares. Uma comparação entre os dados desta pesquisa e as demais elencadas anteriormente pode ser observada no quadro a seguir (Quadro 1).

Quadro 1 - Síntese das pesquisas sobre numeramento.

\begin{tabular}{|c|c|c|l|}
\hline Autor(es) & País & Sujeito(s) investigado(s) & \multicolumn{1}{c|}{ Objetivo(s) } \\
\hline Toledo (2002) & Brasil & $\begin{array}{l}\text { Estudantes do ensino fundamental 2 } \\
\text { da Educação de Jovens e Adultos }\end{array}$ & $\begin{array}{l}\text { Buscar possíveis relações entre o } \\
\text { desenvolvimento de estratégias } \\
\text { metacognitivas e a evolução do registro } \\
\text { matemático dos estudantes }\end{array}$ \\
\hline $\begin{array}{l}\text { Baker, Street e } \\
\text { Tomlin (2003) }\end{array}$ & $\begin{array}{l}\text { Reino } \\
\text { Unido }\end{array}$ & Estudante da educação infantil & $\begin{array}{l}\text { Identificar, analisar e comparar práticas de } \\
\text { numeramento localizadas em diferentes } \\
\text { contextos sociais, especialmente em casas e } \\
\text { escolas. }\end{array}$ \\
\hline $\begin{array}{c}\text { Toledo (2004) } \\
\text { Brasil }\end{array}$ & $\begin{array}{c}\text { Indivíduos considerados de baixo ou } \\
\text { nenhum grau de escolarização, mas } \\
\text { com elevado nível de alfabetismo } \\
\text { matemático, segundo o INAF 2002 }\end{array}$ & $\begin{array}{l}\text { Encontrar possíveis relações entre } \\
\text { numeramento e escolarização }\end{array}$ \\
\hline $\begin{array}{c}\text { Baturo e } \\
\text { Vincent }\end{array}$ & Austrália & Professores do 1º segmento do & Identificar elementos necessários para a \\
\hline
\end{tabular}




\begin{tabular}{|c|c|c|c|}
\hline (2004) & & Ensino Fundamental & $\begin{array}{l}\text { construção de ambiente de aprendizagem que } \\
\text { pudesse promover resultados em termos de } \\
\text { numeramento }\end{array}$ \\
\hline $\begin{array}{l}\text { Faria e } \\
\text { colaboradoras } \\
\quad(2010)\end{array}$ & Brasil & $\begin{array}{c}\text { Estudantes do } 2^{\circ} \text { segmento do Ensino } \\
\text { Fundamental da Educação de Pessoas } \\
\text { Jovens e Adultas }\end{array}$ & $\begin{array}{l}\text { Analisar interações em sala de aula com } \\
\text { abordagem voltada à dimensão sociocultural } \\
\text { das práticas de numeramento e ao seu caráter } \\
\text { discursivo }\end{array}$ \\
\hline $\begin{array}{l}\text { Purpura e } \\
\text { Lonigan } \\
(2013)\end{array}$ & $\begin{array}{l}\text { Estados } \\
\text { Unidos }\end{array}$ & $\begin{array}{l}\text { Estudantes das séries inicias em idade } \\
\text { pré-escolar ( } 3 \text { a } 6 \text { anos de idade) }\end{array}$ & $\begin{array}{l}\text { Validar as estruturas das habilidades } \\
\text { informais de numeramento }\end{array}$ \\
\hline $\begin{array}{c}\text { Fonseca e } \\
\text { Simões (2014) }\end{array}$ & Brasil & $\begin{array}{l}\text { Estudantes de nível intermediário do } \\
\text { ensino fundamental da Educação de } \\
\text { Pessoas Jovens e Adultas }\end{array}$ & $\begin{array}{l}\text { Analisar a posição que os estudantes } \\
\text { assumem no discurso, durante interações } \\
\text { ocorridas em aulas de matemática nas quais } \\
\text { se fazem presentes práticas de numeramento }\end{array}$ \\
\hline $\begin{array}{l}\text { Adelino e } \\
\text { Fonseca } \\
(2014)\end{array}$ & Brasil & $\begin{array}{l}\text { Livros didáticos do } 2^{\circ} \text { segmento do } \\
\text { ensino fundamental da Educação de } \\
\text { Jovens e Adultos }\end{array}$ & $\begin{array}{l}\text { Identificar práticas de numeramento que } \\
\text { contemplem aspectos socioculturais da } \\
\text { matemática, mediante a valorização de } \\
\text { diversos tipos de texto }\end{array}$ \\
\hline $\begin{array}{l}\text { Ferreira e } \\
\text { Fonseca } \\
(2015)\end{array}$ & Brasil & $\begin{array}{l}\text { Estudantes do } 1^{\circ} \text { ano do Ensino } \\
\text { Médio da Educação de Jovens e } \\
\text { Adultos }\end{array}$ & $\begin{array}{l}\text { Encontrar relações entre conhecimentos } \\
\text { cotidianos e escolares presentes em aulas de } \\
\text { matemática }\end{array}$ \\
\hline
\end{tabular}

Fonte: Elaborado pelos autores.

A quantidade de pesquisas que envolvem a questão do numeramento ainda é pequena, se comparada com outros temas, e, além disso, ainda não verificamos esse tipo de investigação pautado em recursos como computadores, tablets ou smartphones, tecnologias que apresentam o caráter digital. Desta forma, desprovidos dessa literatura, sentimo-nos inclinados a recorrer aos estudos sobre multiletramento, embora não pertença ao contexto específico da educação matemática, a fim de verificar como os perscrutadores das linguagens vêm trabalhando com esses recursos.

\section{Telas multiletradas}

Assim como no letramento e no numeramento, estudiosos do multiletramento (MARQUES, 2016; COSCARELLI; KERSCH, 2016; CANI; COSCARELLI, 2016; ROJO, 2013) sinalizam que essa modalidade está imbricada de práticas sociais, as quais têm sido afetadas pela constante presença da Internet e dos recursos midiáticos, capazes de produzir hipertextos cada vez mais dinâmicos e interativos, uma vez que "[...] cada indivíduo se encontra imerso em textos multissemióticos, compostos por diversas linguagens, culturas, mídias e tecnologias” (MARQUES, 2016, p. 115), sendo exigidas mais habilidades para lidar com esse novo tipo de comunicação. Além de abarcar o cotidiano, o multiletramento carrega consigo não só a perspectiva da multiplicidade de formas de comunicação proporcionadas pela tecnologia, como a pluralidade e diversidade linguística e cultural da sociedade contemporânea (COSCARELLI; KERSCH, 2016). 
Crianças que sequer sabem ler ou escrever demonstram habilidades para explorar aplicativos de jogos em smartphones, os quais trazem linguagem híbrida e recursos multimodais como cores, sons, figuras, músicas, sem a interferência ou auxílio de qualquer pessoa mais experiente. Rojo (2012) sinaliza que essa tecnologia possui grande potencial a ser aproveitado em sala de aula para práticas de multiletramento e, dessa forma, não deveria ser proibido, mas utilizado como recurso multimidiático que agrega potencialidades para a construção/leitura/interpretação de hipertextos. A fim de esclarecer um pouco mais, trazemos duas pesquisas acerca dessa pedagogia.

Cani e Coscarelli (2016) discutiram a maneira como as leituras dos textos multimodais podem se constituir em práticas pedagógicas, a partir da análise, sob a ótica da Teoria da Multimodalidade e da Gramática do Design Visual (KRESS; VAN LEEUWEN, 2006), de uma aula integrante do Portal do Professor, focada em textos multimodais, e de uma proposta sobre multimodalidade idealizada por alunas do primeiro período do curso de licenciatura em letras da Universidade Federal de Minas Gerais.

Ao introduzirem no mecanismo de busca do referido site o verbete multimodalidade, as estudiosas obtiveram como resultados cinco exemplos de aulas, das quais elegeram para seu estudo "Textos multimodais na escola: você trabalha?", por se tratar daquela que apresentava em seu título a palavra multimodal, pela menção direta realizada pela professora elaborada da aula a autores que tratam da multimodalidade (Kress e Van Leeuwen), por apresentar comentários de usuários a seu respeito e por ser a de maior número de acessos. Refere-se a uma atividade com estimativa de duração de três aulas de cinquenta minutos cada, cujos recursos e estratégias sugeridas para sua implementação eram o uso da Internet e do projetor multimídia, a produção de vídeos e de textos no word, além da criação de um blog.

As pesquisadoras estabeleceram como critérios para a realização da análise (i) a reflexão sobre o significado das imagens no texto, (ii) a exploração de diferentes textos multimodais e (iii) a produção desse tipo de obra. Sobre a questão das imagens, o estudo revelou que aquela proposta de aula utiliza tanto textos em que elas podem ser retiradas sem qualquer prejuízo à interpretação, como outros nos quais as imagens são integrantes fundamentais para compor uma unidade semiótica. Desta forma, Cani e Coscarelli (2016) perceberam que a sugestão de leitura pouco se preocupa com a abordagem da multimodalidade, ou seja, há escassa ou nenhuma exploração de diferentes textos multimodais, o que também não estabelece uma relação entre esse tipo de leitura e a produção final sugerida para os alunos, um manual de instruções.

Ao analisar a proposta das estudantes de licenciatura, a qual consistia no desenvolvimento de um anúncio de gênero publicitário, as investigadoras revelaram que, em relação ao significado

\footnotetext{
${ }^{2}$ Disponível em http://portaldoprofessor.mec.gov.br/fichaTecnicaAula.html?aula=51782, acesso em 07/03/2017.
} 
das imagens no texto, a atividade apresenta rico potencial para polemizar com os alunos, embora tenham considerado que haja pouca integração entre a mensagem veiculada e o público a quem se destina. De forma semelhante ocorreu quanto à categoria de exploração de textos multimodais, pois, mesmo apresentando uma perspectiva na qual se propõe a percepção e a manipulação de textos, o anúncio apresentou carência de unidades linguísticas próprias do gênero. Já no quesito produção de textos multimodais, a atividade deu indícios de favorecer a abordagem do conceito de multimodalidade, uma vez que os sujeitos envolvidos parecem ter construído ativamente seus significados.

As perscrutadoras sinalizam que a interpretação de textos multimodais requer certo cuidado nas práticas pedagógicas, pois o que se observou nas propostas analisadas foi a intencionalidade de usar o conhecimento cotidiano para alicerçar a leitura multimodal. No Portal do Professor o trabalho permanece engessado no sentido de favorecer interpretações focadas na linguagem escrita, com rara exploração dos recursos semióticos em jogo, ao passo que houve destaque à multiplicidade de linguagens e de modos semióticos pelas estudantes de licenciatura na proposta de aula por elas sugerida. Desta forma, sublinham a necessidade de discussão acerca da incorporação de novas metodologias nos ambientes de aprendizagem, principalmente no que tange os recursos semióticos.

Mediante a implementação do projeto "Eu sou João Goulart" (não se refere ao político, mas ao nome da escola), Marques (2016) investigou a possibilidade de ampliação do desenvolvimento da linguagem escrita mediado por recursos multimodais e a construção de novos significados por dezoito alunos, entre quatorze e dezesseis anos, do $9^{\circ}$ ano do ensino fundamental de uma escola pública, situada em um bairro de vulnerabilidades sociais, justificando a escolha do seu público a fato de serem estudantes formandos, ou seja, prestes a deixar aquela instituição de ensino.

“Eu sou João Goulart” foi elaborado como um Projeto Didático de Gênero que apresenta a interação, o trabalho coletivo, a prática social e a aprendizagem de ambos, professores e alunos, como concepção de linguagem, estimulando-os à posição de responsáveis pela autoria e produção de gênero, explorando, por exemplo, campanha e anúncio publicitários, oficinas interativas e customização de camisetas. Os aprendizes foram levados a refletir acerca das condições da escola (depredação, desvalorização e possíveis soluções) e das relações entre estudantes/comunidade e a instituição de ensino (o papel de cada um e o que a escola representa para eles). As oficinas, que se centraram em estudos linguísticos regulares no gênero anúncio publicitário, e a mediação por diferentes tecnologias possibilitaram que o grupo se apropriasse desse gênero e fosse capaz de produzir nove anúncio publicitários, a partir das reflexões sugeridas inicialmente. 
Ao analisar a produção dos textos multimodais dos seus sujeitos de pesquisa, a estudiosa salientou que, embora a relação entre imagem e texto não seja fácil de ser produzida quando se tem um objetivo a ser alcançado e os atores são reais, houve coesão multimodal entre palavras e imagens, revelando uma relação coerente. Ao serem colocados na posição de produtores, os aprendizes, que trabalharam em duplas, tiveram de assumir uma tomada de decisão para mesclar os elementos multimodais e produzir seus significados para a sociedade.

Marques (2016) sublinha que, com o uso de tecnologias, destacando-se o celular como ferramenta mais utilizada por disponibilizar aplicativos com recursos modernos, de recursos midiáticos e de redes sociais, foi possível aproximar os estudantes às práticas de letramento digital, nas quais emergiram novas capacidades multissemióticas relacionadas à produção de gêneros textuais. No entanto, salienta a autora, há de ser adotada uma nova concepção de ensino que garanta o uso adequado de novas tecnologias em sala de aula que valorizem as práticas sociais.

Face ao exposto, parece-nos que a perspectiva do multiletramento, embora não se trate de uma pedagogia de cunho matemático, converge com o nosso propósito de investigar sobre práticas de numeramento mediante a inserção de smartphones em aulas de matemática, uma vez que a utilização de aplicativos na resolução de problemas pode se aproximar das possibilidades que os recursos multimidiáticos proporcionam à elaboração do hipertexto. Desta forma, elaboramos uma atividade preambular, conforme indicada a seguir.

\section{Telas em elaboração}

Como uma pesquisa embrionária, o que temos ainda são grandes expectativas em relação à implementação que pretendemos realizar. No momento, estamos focados no aplicativo gratuito MyScript Calculator ${ }^{3}$, por proporcionar a escrita livre na própria tela da operação, o qual permite realizar operações como adição, subtração, multiplicação, divisão, potenciação, radiciação, frações e logaritmos. Associando-o às atividades instigadoras, foi pensado o seguinte problema: sabendo-se que você só dispõe de notas de R\$5,00, quantas notas são necessárias para pagar uma compra que totalizou $R \$ 75,00$ ? Como os alunos iriam manipular a tela para resolver essa tarefa?

Ao ministrarmos oficina para estudantes do Ensino Médio de uma escola da rede pública, utilizamos essa atividade e duas formas de resolução foram apresentadas. Uma discente que preferiu trabalhar sozinha, Mariah $^{4}$, revelou ter utilizado o aplicativo para fazer uma sequência de adições (5 $+5+5+\ldots)$ até encontrar o valor a ser pago $(\mathrm{R} \$ 75,00)$ e depois contou quantas vezes repetiu o

\footnotetext{
${ }^{3}$ Disponível em https://play.google.com/store/apps/details?id=com.visionobjects.calculator

${ }^{4}$ Os nomes dos estudantes são fictícios, a fim de lhes preservar o anonimato.
} 
número 5, justificando seu procedimento da seguinte forma: professor, o que eu fiz foi pegar as notas que eu tinha de 5 e ir somando até chegar em 75. Aí depois foi só contar.

Figura 1 - Resolução apresentada por Mariah
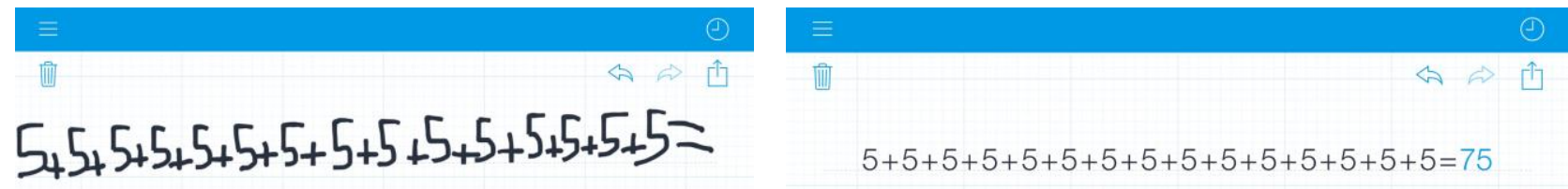

$5+5+5+5+5+5+5+5+5+5+5+5+5+5+5=75$

Fonte: Fragmento de pesquisa.

Dois outros alunos que labutaram em dupla, Pedro e Gustavo, apresentaram sua escolha por tentativas mediante a multiplicação $(5 \times 1,5 \times 2,5 \times 3, \ldots)$, efetuando a operação até que o resultado fosse o número 75 (Figura 2). O senhor não perguntou quantas notas a gente ia gastar? Então é conta de vezes. Pronto, só multiplicar até encontrar 75.

Figura 2 - Resolução apresentada por Pedro e Gustavo

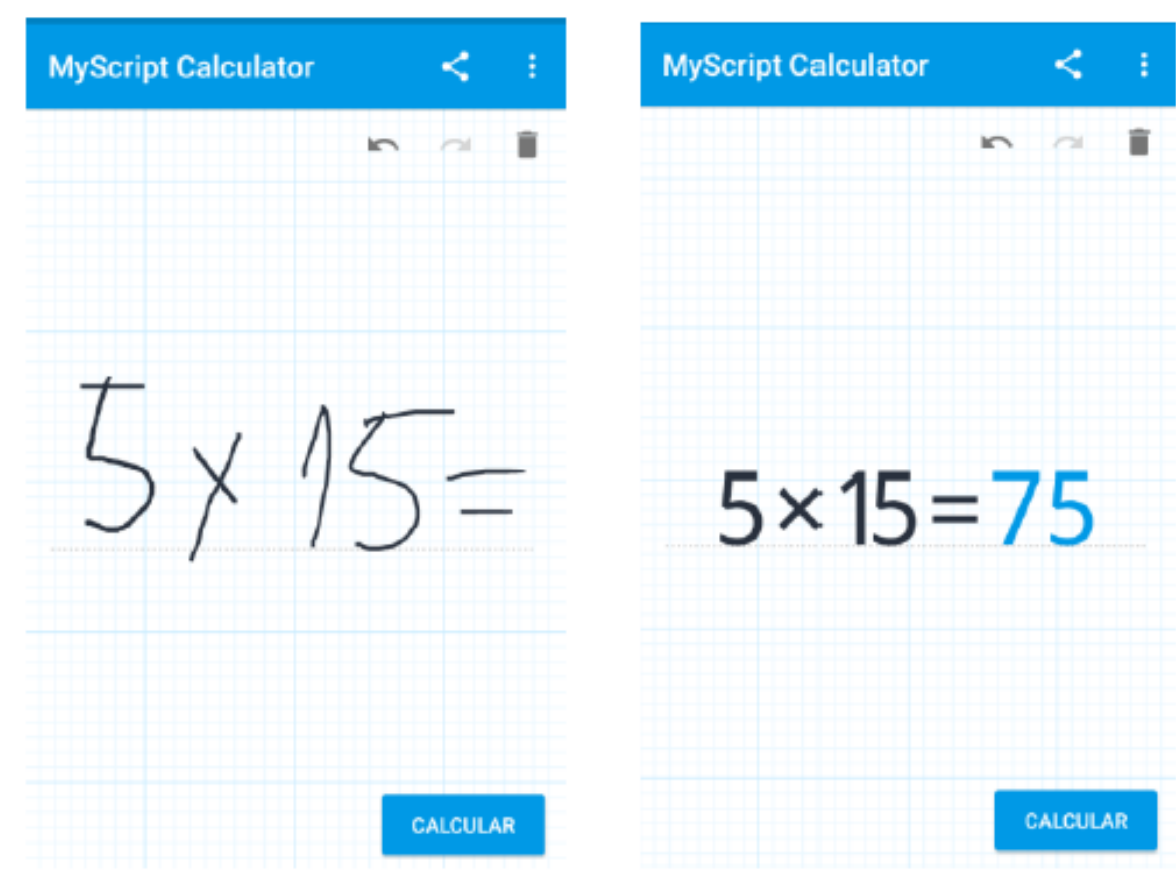

Fonte: Fragmento de pesquisa.

\section{À luz das telas}

Face às pesquisas apresentadas, nos permitimos realizar algumas sinalizações iniciais. Tratando-se dos sujeitos envolvidos, as investigações de âmbito nacional (TOLEDO, 2002, 2004; ADELINO; 
FONSECA, 2014; FERREIRA; FONSECA, 2015) têm apontado para o público matriculado no programa de Educação de Jovens e Adultos, ou seja, indivíduos de certa idade que ingressaram tardiamente na educação formal, ao passo que as apreciações realizadas fora de nosso país (BAKER; STREET; TOMLIN, 2003; PURPURA; LONIGAN, 2013), têm sido direcionadas à observação das séries iniciais. Já Baturo e Vincent (2004) preocuparam-se com estratégias, posicionamentos e comportamentos docentes, sem que conseguíssemos identificar o nível escolar dos alunos implicados.

É importante salientarmos que, até o presente momento, encontramos apenas um dos estudos (FARIA; GOMES; FONSECA, 2010) no qual emergiu um recurso tecnológico, a calculadora, embora não tivesse sido pensada anteriormente a sua utilização pelas pesquisadoras. Ao introduzirmos o smartphone com o aplicativo MyScript Calculator na oficina ministrada, em uma análise preliminar, parece-nos que a resolução apresentada por Mariah carrega indícios de numeramento do cotidiano, uma vez que a mesma relatou uma prática do seu dia a dia (BARWELL, 2004), que a ajudou a resolver o problema, ao dizer que pegaria as notas que tinha e somaria até chegar ao valor desejado, como se faz quando se deseja pagar algo que se esteja comprando. Por outro lado, Pedro e Gustavo aparentaram caminhar para prática de numeramento escolar (BAKER; STREET; TOMLIN, 2003) ao relacionarem a quantidade de notas à ideia de multiplicação, ou seja, o número que multiplicasse o 5 (valor da nota) e encontrasse o 75 (valor total a ser pago).

\section{Telas se apagando}

Não tivemos a intenção aqui de discutir sobre o conceito de numeramento, o qual vai bem além das práticas apresentadas. Até porque pensamos que o numeramento, nos dias de hoje, envolve um conjunto de ações (numéricas, figurais, pictóricas, geométricas, de expressão gestual, etc) que podem compor o espectro dos processos de ensino e aprendizagem na Educação Básica. No entanto, os pais de Aaysha (BAKER; STREET; TOMLIN, 2003) perceberam que sua filha, embora tivesse aprendido uma maneira de contar de três em três no seu dia a dia, conseguia também, depois de ir para a escola, realizar bem a contagem da forma lá aprendida, o que revela duas possíveis formas de numeramento, sendo um do cotidiano e o outro escolar. Nosso desafio reside na exploração das práticas de numeramento mediante a utilização de atividades instigadoras associadas à tecnologia touchscreen ou, mais especificamente, ao smartphone. Então, nos perguntamos: se $o$ multiletramento trata de práticas que se apropriam das tecnologias digitais, por permitirem várias alternativas de escrita e de comunicação, e os estudos de numeramento ainda não o fazem, será que não estaríamos à procura de uma nova possibilidade de numeramento? 


\section{Referências}

ADELINO, P. R.; FONSECA, M. C. F. R. Matemática e texto: práticas de numeramento num livro didático da educação de pessoas jovens e adultas. Revista Brasileira de Educação, v. 19, n. 56, jan-mar, 2014, p. 181-200.

BAKER, D.; STREET, BRIAN; TOMLIN, A. Mathematics as social: understanding relationships between home and school numeracy practices. For the Learning of Mathematics, v. 23, n. 3, 2003, p. 11-15.

BARWELL, R. What is numeracy? For the Learning of Mathematics, v. 24, n. 1, 2004, p. 20-22.

BATURO, A. R.; VINCENT, J. Teachers enhancing numeracy. Australian Primary Mathematics Classroom, v. 9, n. 4, 2004, p. 54-56.

BRASIL. Secretaria de Educação Fundamental. Parâmetros curriculares nacionais: Matemática. Brasília: MEC /SEF, 1998.

CANI, J. B.; COSCARELLI, C. V. Textos multimodais como objetos de ensino: reflexões em propostas didáticas. KERSCH, D. F.; COSCARELLI, C. V.; CANI, J. B. (orgs.). Multiletramentos e multimodalidade: ações pedagógicas aplicadas à linguagem. Campinas: Pontes Editores, 2016.

COSCARELLI, C. V.; KERSCH, D. F. Pedagogia dos multiletramentos: alunos conectados? Novas escolas + novos professores. In: KERSCH, D. F.; COSCARELLI, C. V.; CANI, J. B. (orgs.).

Multiletramentos e multimodalidade: ações pedagógicas aplicadas à linguagem. Campinas: Pontes Editores, 2016.

ESTEBAN, M. P. S. Pesquisa qualitativa em educação: fundamentos e tradições. Porto Alegre: Artmed, 2010.

FERREIRA, A. R. C.; FONSECA, M. C. F. R. Práticas de numeramento no Ensino Médio da EJA: reflexões para a sala de aula. Cadernos de Educação, n. 52, 2015, p. 1-17.

KRESS, G.; VAN LEEUWEN, T. Reading images: the gramar of visual design. Londres: Routledge, 2006.

MARQUES, R. G. Campanha publicitária, tecnologias e (re)construção de identidades no espaço escolar. KERSCH, D. F.; COSCARELLI, C. V.; CANI, J. B. (orgs.). Multiletramentos e multimodalidade: ações pedagógicas aplicadas à linguagem. Campinas: Pontes Editores, 2016.

MARQUES, W., BAIRRAL, M. Na calculadora é ponto ou vírgula? Analisando interações discentes sob as lentes de Vygotsky e Bakhtin. Seropédica, RJ: EDUR, 2014.

PURPURA, D. J.; LONIGAN, C. J. Informal numeracy skills: the structure and relations among numbering, relations, and arithmetic operations in preschool. American Educational Research Journal, v. 50, n. 1, 2013, p. 178-209.

ROJO, R. Pedagogia dos multiletramentos: diversidade cultural e de linguagens na escola. ROJO, R. (org.). Escol@ conectada: os multiletramentos e as TICs. São Paulo: Parábola, 2013.

ROJO, R. Gêneros discursivos do Círculo de Bakhtin e multiletramentos. ROJO, R.; MOURA, E. (orgs.). Multiletramentos na escola. São Paulo: Parábola, 2012.

SPINILLO, A. G., LAUTERT, S. L. Pesquisa-intervenção em psicologia do desenvolvimento cognitivo: princípios metodológicos, contribuição teórica e aplicada. CASTRO, L. R., BESSET, V. L. (orgs.). Pesquisa-intervenção na infância e juventude. Rio de Janeiro: Trarepa/FAPERJ, 2008.

TOLEDO, M. E. R. O. Numeramento, metacognição e aprendizagem matemática de jovens e adultos. Anais da 25 ${ }^{\mathrm{a}}$ Reunião Anual da Associação Nacional de Pós-Graduação e Pesquisa em Educação - ANPED, Caxambu, 2002. 
TOLEDO, M. E. R. O. Numeramento e escolarização: o papel da escola no enfrentamento das demandas matemáticas cotidianas. FONSECA, M. C. F. R. (org.). Letramento no Brasil: habilidades matemáticas. São Paulo: Global, 2004.

Submetido em janeiro de 2017 Aprovado em março de 2017 